\title{
Use of STATCOM for Improving Dynamic Performance of Wind Farms Connected in Power Grid
}

\author{
K. B. Mohd. Umar Ansari ${ }^{1}$ \\ PG Student [EPES], Dept. of EEE, AKG Engineering College, Ghaziabad, Uttar Pradesh, India ${ }^{1}$
}

\begin{abstract}
When integrated to the power system, large wind farms pose stability and control issues. A thorough study is needed to identify the potential problems and to develop measures to mitigate them. Although integration of high levels of wind power into an existing transmission system does not require a major redesign, it necessitates additional control and compensating equipment to enable recovery from severe system disturbances. This paper investigates the use of a Static Synchronous Compensator (STATCOM) along with wind farms for the purpose of stabilizing the grid voltage after grid-side disturbances such as a three phase short circuit fault, temporary trip of a wind turbine and sudden load changes. The strategy focuses on a fundamental grid operational requirement to maintain proper voltages at the point of common coupling by regulating voltage. The DC voltage at individual wind turbine (WT) inverters is also stabilized to facilitate continuous operation of wind turbines during disturbances.
\end{abstract}

KEYWORDS: STATCOM, Bus bar, Wind turbines, Wind Generation, Transient Stability.

\section{I.INTRODUCTION}

Now a day's wind as a significant proportion of non pollutant energy generation is widely used. The wind farm capacity is being continuously increased through the installation of more and larger wind turbines. Voltage stability and an efficient fault ride through capability are the basic requirements for higher penetration. Wind turbines have to be able to continue uninterrupted operation under transient voltage conditions.

One of the major issues concerning a wind farm interconnection to a power grid concerns its dynamic stability on the power system. Voltage instability problems occur in a power system that is not able to meet the reactive power demand during faults and heavy loading conditions. A wind farm is usually spread over a wide area and has many wind generators, which produce different amounts of power as they are exposed to different wind patterns.

Flexible AC Transmission Systems (FACTS) such as the Static Synchronous Compensator (STATCOM) and the Unified Power Flow Controller (UPFC) are being used extensively in power systems because of their ability to provide flexible power flow control. The main motivation for choosing STATCOM in wind farms is its ability to provide bus bar system voltage support either by supplying and/or absorbing reactive power into the system.

In this paper, a STATCOM is added to the power network to provide dynamic voltage control for the wind farm, dynamic power flow control for the transmission lines, relieve transmission congestion and improve power oscillation damping. Simulation results show that the STATCOM devices significantly improve the performance of the wind farm and the power network during transient disturbances.

\section{II.STUDIED SYSTEM AND ITS SIMULINK MODEL}

A wind farm consisting of six 1.5-MW wind turbines is connected to a $25-\mathrm{kV}$ distribution system exports power to a $120-\mathrm{kV}$ grid through a $25-\mathrm{km} 25-\mathrm{kV}$ feeder as shown in Fig.1. The studied power system is simulated using Simulink Matlab software package as shown in fig 2. This paper discussed the effect of speed on wind turbines, on the studied system which depicts the following: wind turbine rotor speed, active, reactive power, and voltage on $25 \mathrm{kV}$ bus with and without STATCOM. 


\section{International Journal of Advanced Research in Electrical,} Electronics and Instrumentation Engineering

(An ISO 3297: 2007 Certified Organization)

\section{Vol. 3, Issue 9, September 2014}

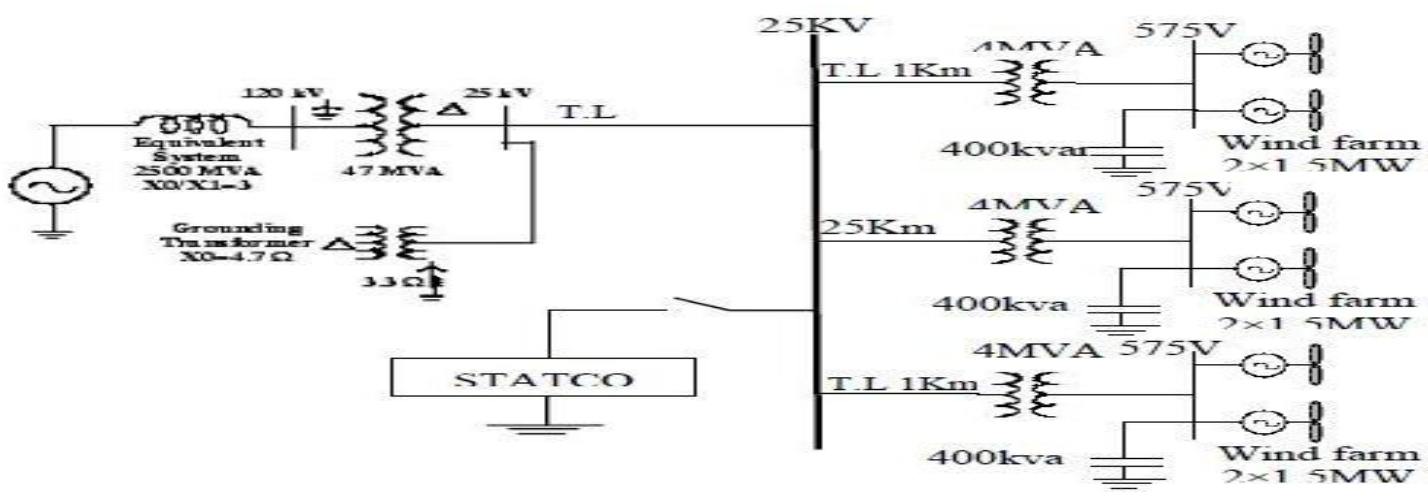

Fig.1 TEST SYSTEM
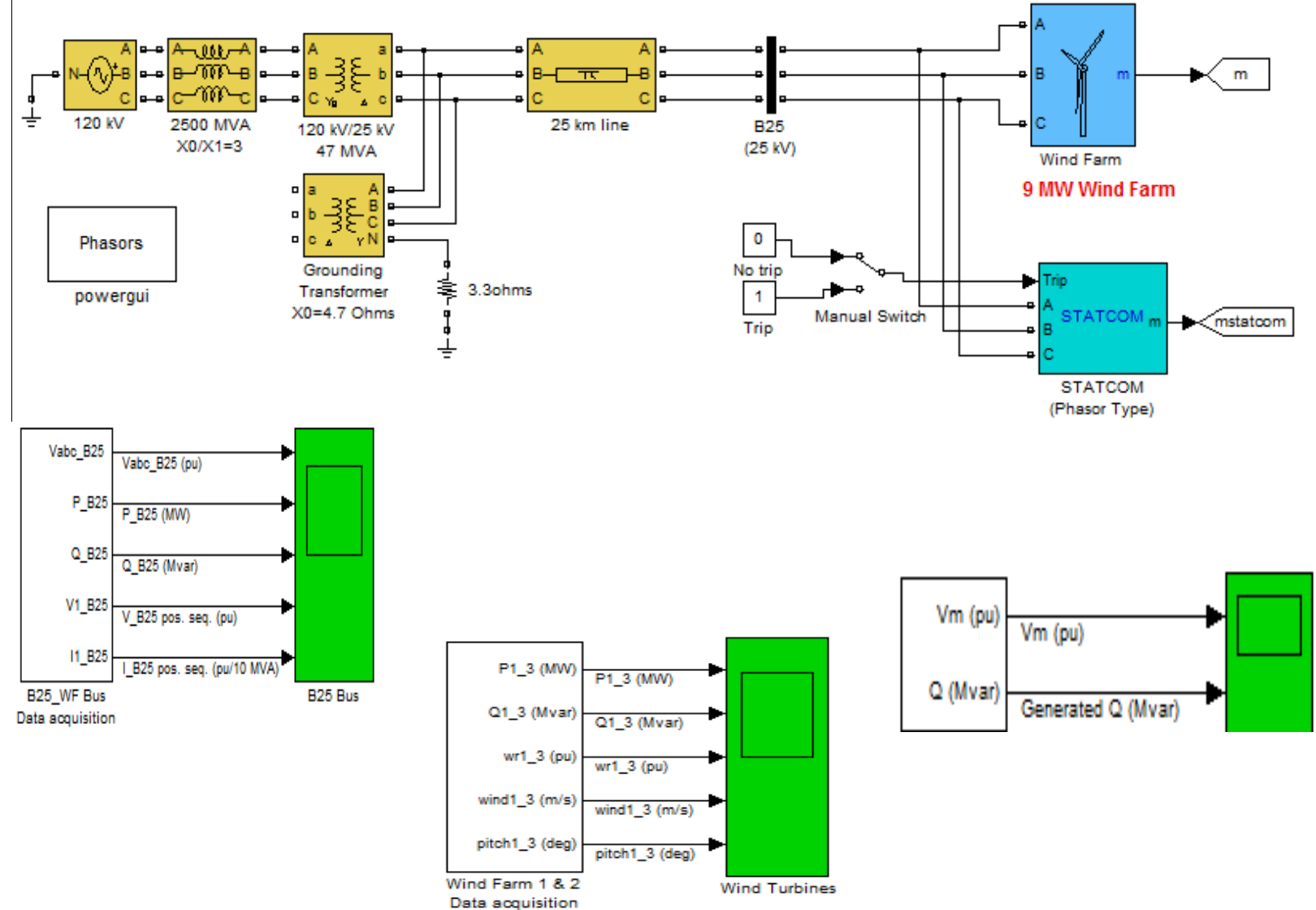

Wind Farm (IG)

Fig.2 Simulink Model

The 9-MW wind farm is simulated by three pairs of 1.5 MW wind-turbines as shown in Fig. 2(a) \& in Fig. 2(b).Wind turbines use squirrel-cage induction generators (IG) as shown in Fig. 2(a) \& in Fig. 2(b).

Reactive power absorbed by the IGs is partly compensated by capacitor banks connected at each wind turbine low voltage bus (400 kvar for each pair of $1.5 \mathrm{MW}$ turbine). The rest of reactive power required to maintain the $25-\mathrm{kV}$ voltage at bus B25 close to 1 pu is provided by a 3-Mvar STATCOM with a 3\% droop setting. 


\section{International Journal of Advanced Research in Electrical, Electronics and Instrumentation Engineering (An ISO 3297: 2007 Certified Organization)}

\section{Vol. 3, Issue 9, September 2014}

The stator winding is connected directly to the $60 \mathrm{~Hz}$ grid and the rotor is driven by a variable-pitch wind turbine.

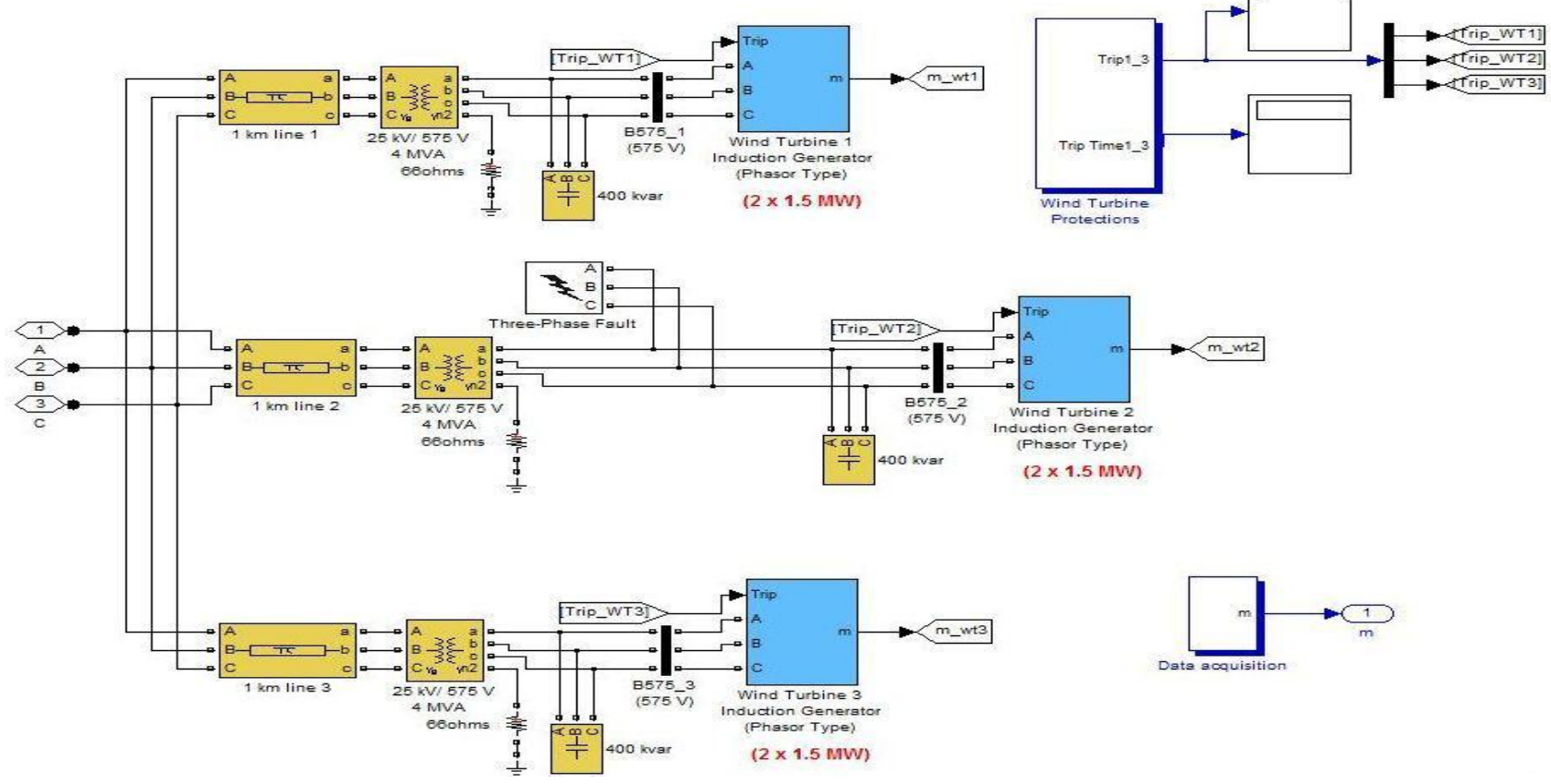

Fig. 2(a) Detailed model of Wind Farm when fault is at Generator 2

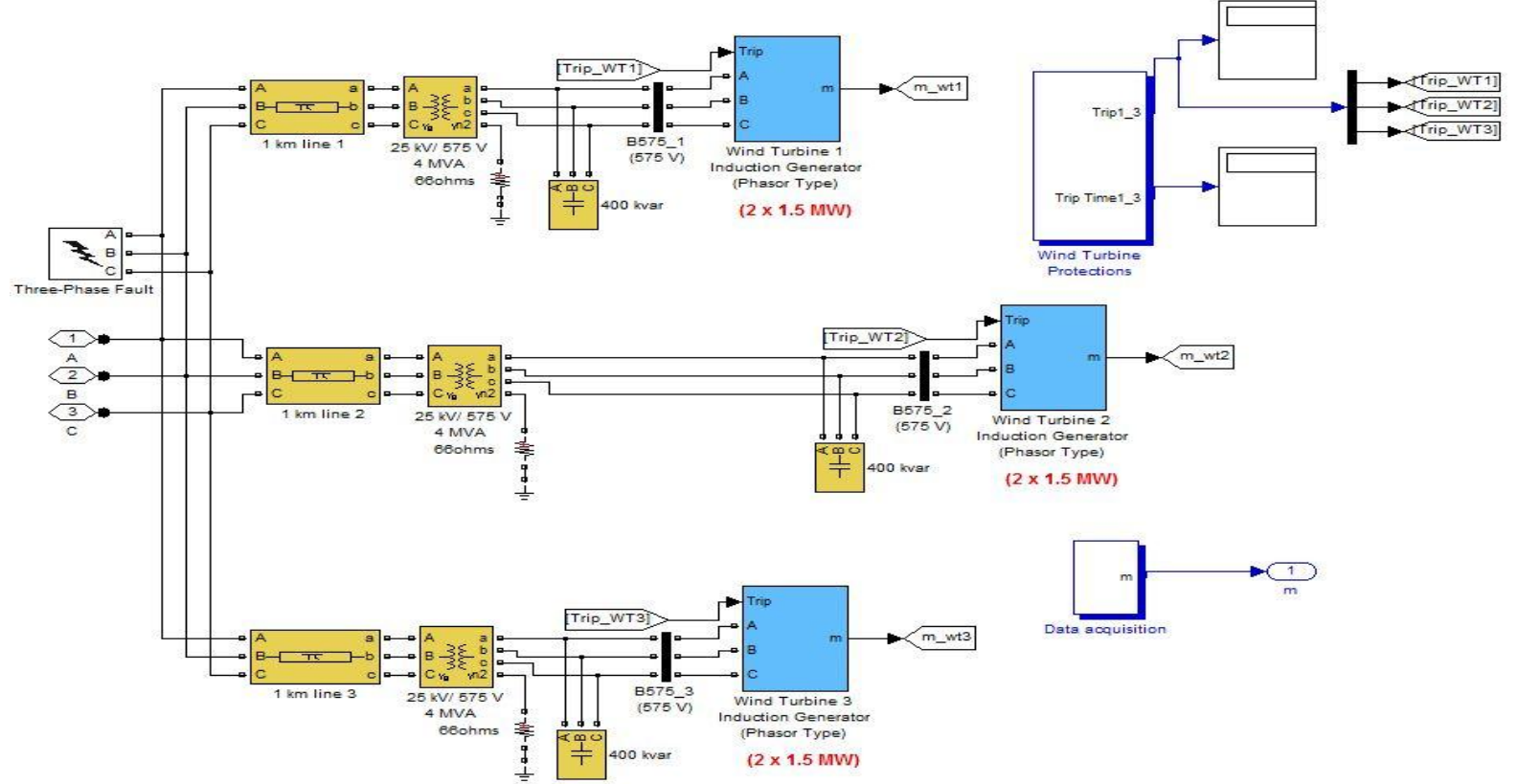

Fig. 2(b) Detailed model of Wind Farm when fault is at Bus 25

The pitch angle is controlled in order to limit the generator output power at its nominal value for winds exceeding the nominal speed $(9 \mathrm{~m} / \mathrm{s})$. 


\section{International Journal of Advanced Research in Electrical, Electronics and Instrumentation Engineering}

\section{(An ISO 3297: 2007 Certified Organization)}

\section{Vol. 3, Issue 9, September 2014}

In order to generate power the IG speed must be slightly above the synchronous speed. Speed varies approximately between $1 \mathrm{pu}$ at no load and $1.005 \mathrm{pu}$ at full load. Each wind turbine has a protection system monitoring voltage, current and machine speed. As shown below:
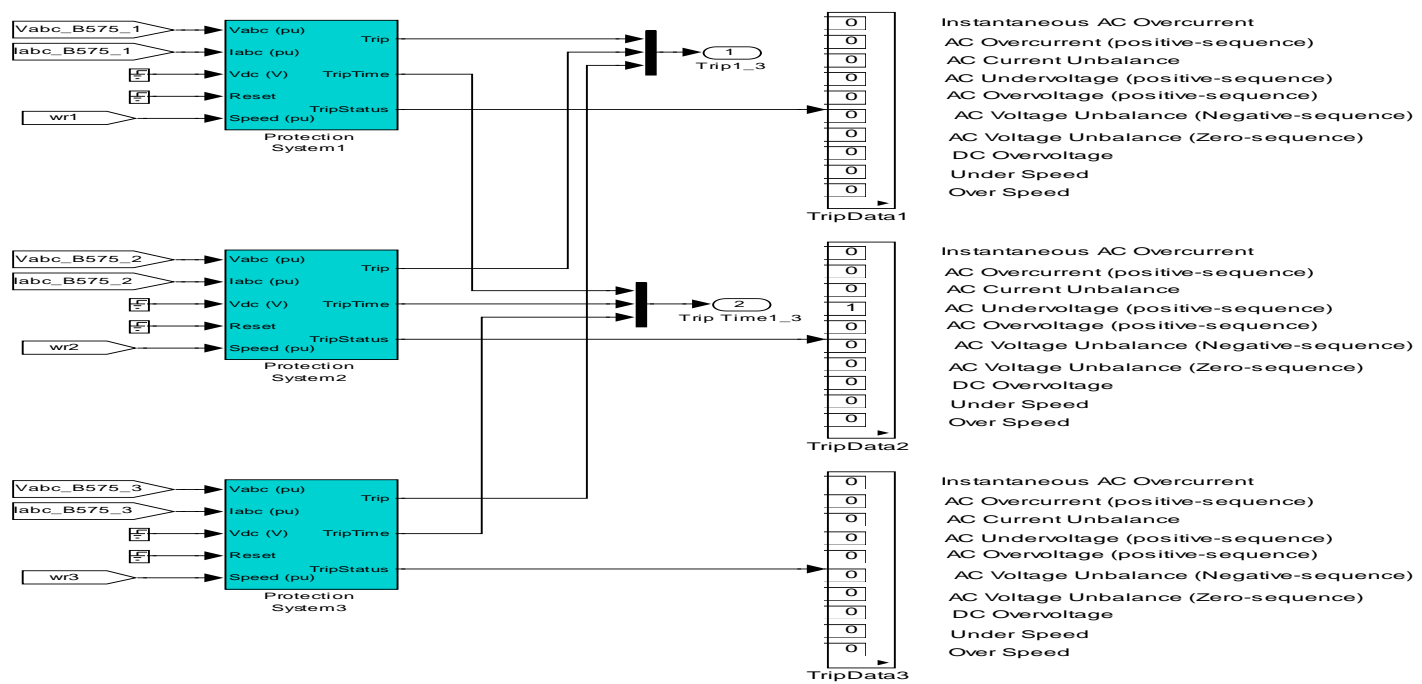

A: Description of the data Acquisition circuit:
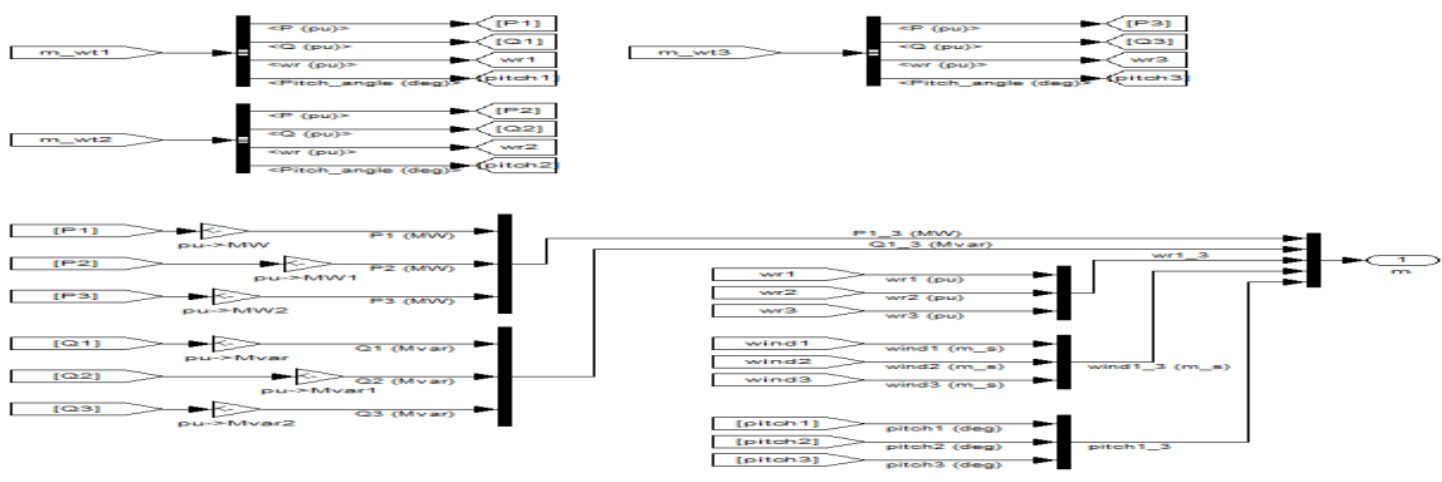

B: Data Acquisition circuit for $25 \mathrm{kv}$ bus:

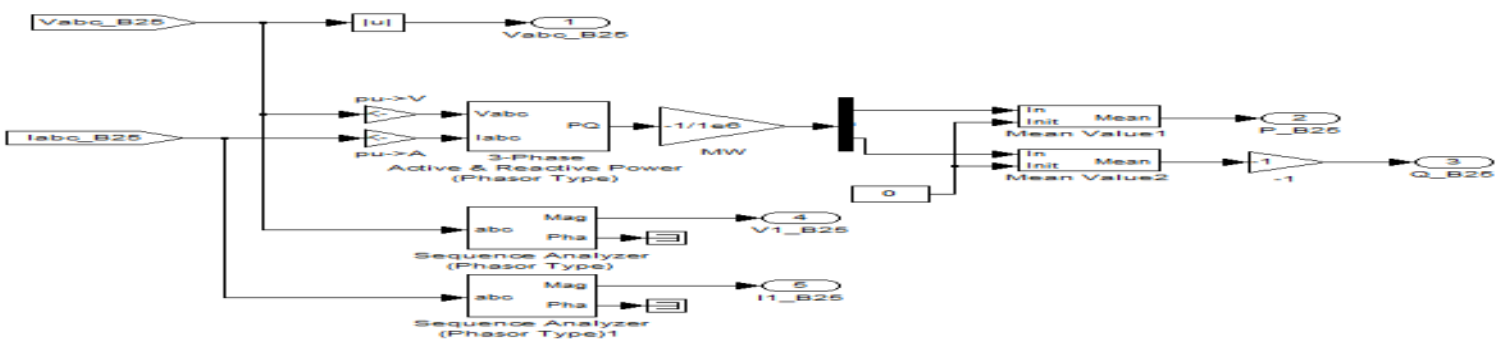

It receive signal from the power_wing_ig/B25(25kv)/vabc. This is already defined in the toolbox.

\section{C: Data Acquisition circuit of the STATCOM:}




\section{International Journal of Advanced Research in Electrical, Electronics and Instrumentation Engineering}

(An ISO 3297: 2007 Certified Organization)

Vol. 3, Issue 9, September 2014

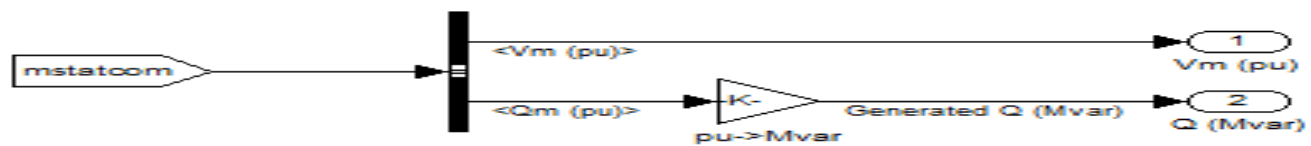

It receive signal from the power_wing_ig/goto1 i.e from the STATCOM which is already defined in the toolbox.

D: Data Acquisition circuit of wind farm for wind turbine:

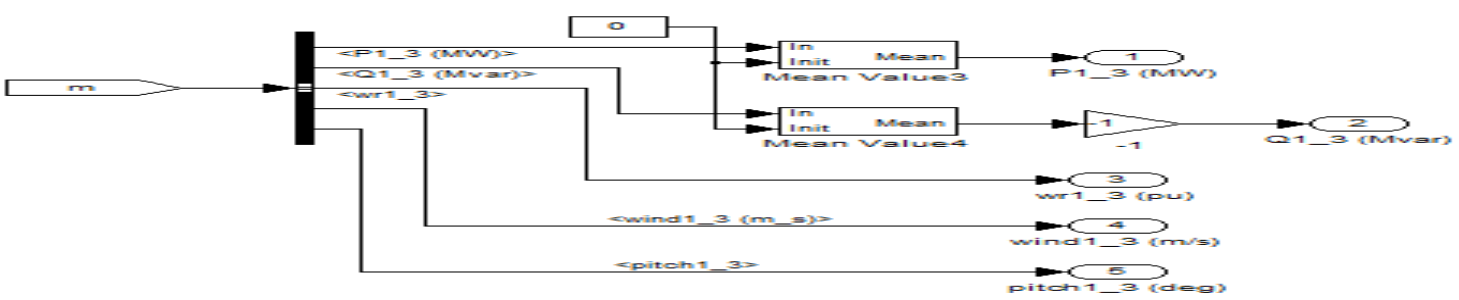

In above circuit, input is taken from output of the data main acquisition circuit of the wind farm.

III.RESPONSE OF THE SYSTEM WITH 3 MVAR STATCOM WHEN FAULT IS AT GENERATOR 2 at (3ms-3.1ms)

\section{CASE 1: WITHOUT FAULT CONDITION}

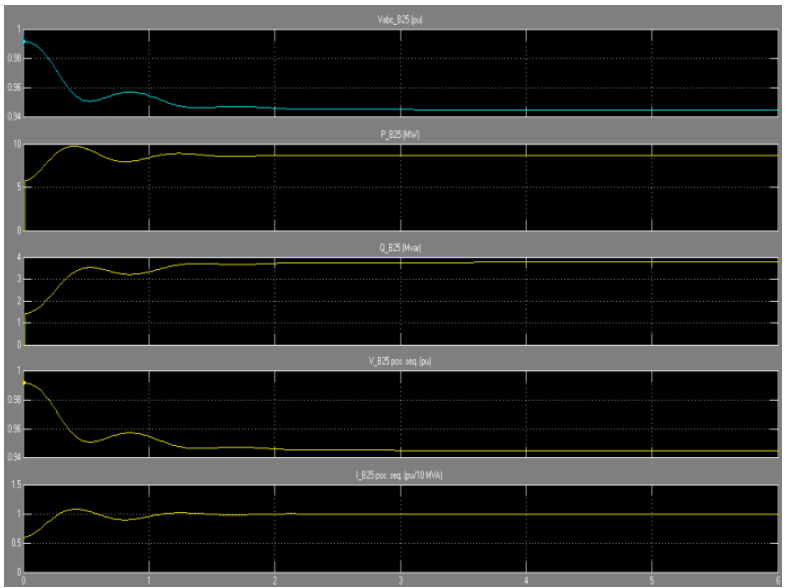

3.1(a) at system bus

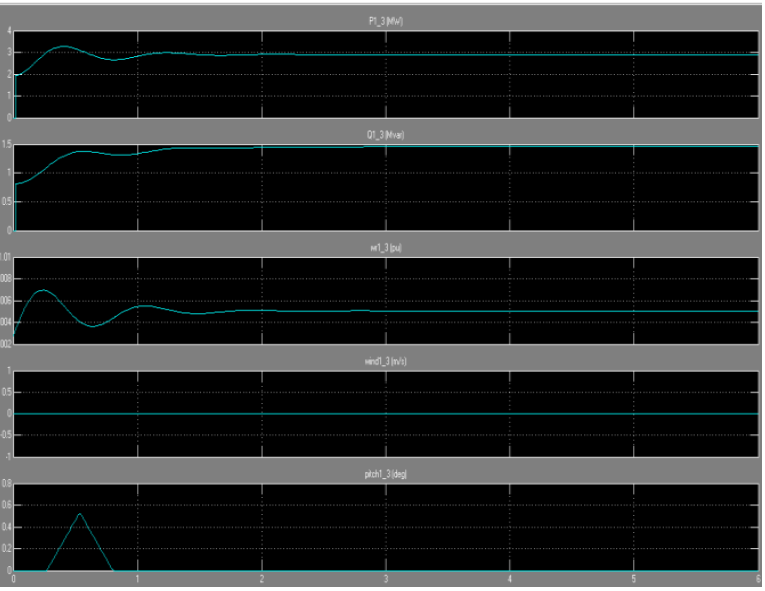

3.1(b) at generators

Fig.3.1. Response of the system without fault and without STATCOM

When the wind speed is set at $9 \mathrm{~m} / \mathrm{s}$, then it is observed from Fig. 3.1(b) the output active power for each pair of turbine is $3 \mathrm{MW}$, absorbed reactive power for each pair of turbine reaches $1.47 \mathrm{Mvar}$, turbine speed for each pair of turbine reaches to $1.005 \mathrm{pu}$ as shown in Fig. 3.1(b). Because of the lack of reactive power support the voltage at bus $25 \mathrm{kV}$ now drops to 0.945 pu as shown in Fig. 3.1(a). 


\section{International Journal of Advanced Research in Electrical, Electronics and Instrumentation Engineering}

(An ISO 3297: 2007 Certified Organization)

\section{Vol. 3, Issue 9, September 2014}

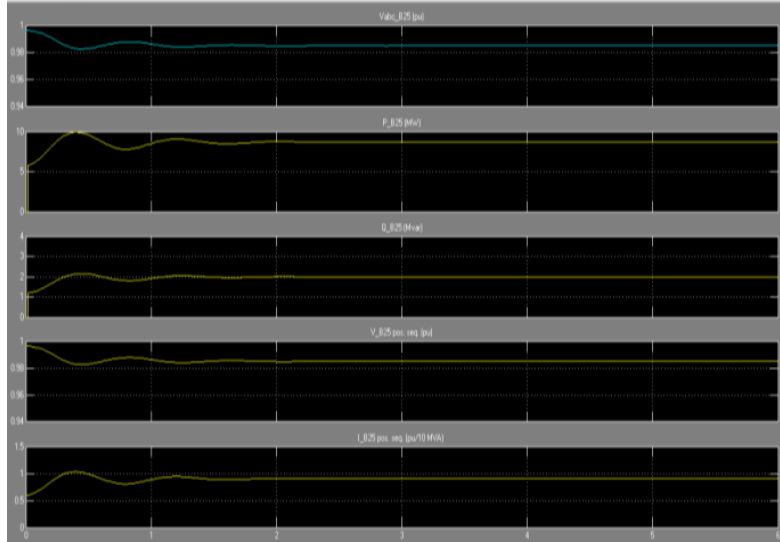

3.2(a) at system bus

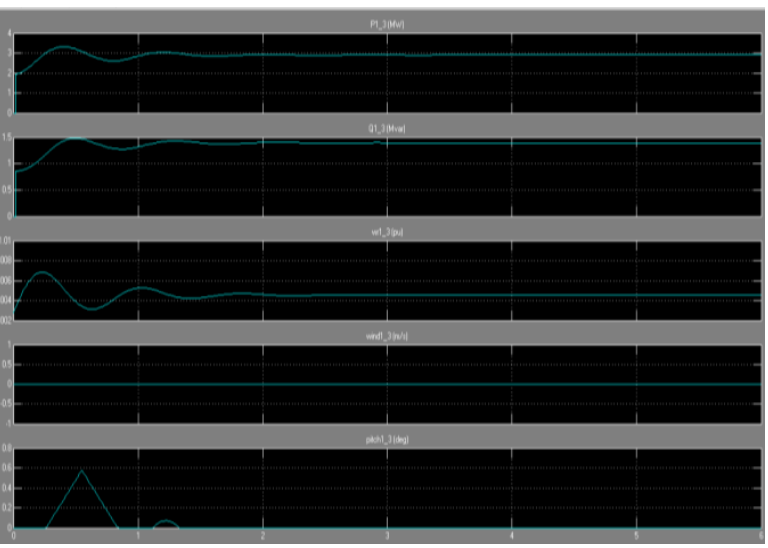

3.2(b) at generators

Fig.3.2. Response of the system without fault and with STATCOM

While with STATCOM the output active power for each pair of turbine is $3 \mathrm{MW}$, absorbed reactive power for each pair of turbine reaches 1.47Mvar, turbine speed for each pair of turbine reaches to 1.0045pu as shown in Fig. 3.2(b). With respect bus $25 \mathrm{kV}$, voltage reaches to $0.985 \mathrm{pu}$ in Fig. 3.2(a), active power reaches to 8.9MW and absorbed reactive power is 2.08Mvar.

\section{CASE 2: PHASE TO PHAE TO GROUND FAULT CONDITION}

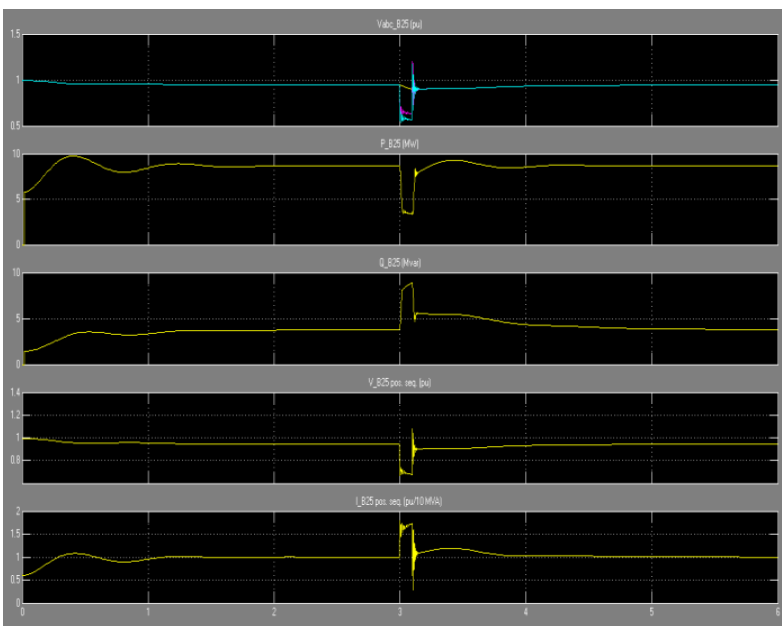

3.3(a) at system bus

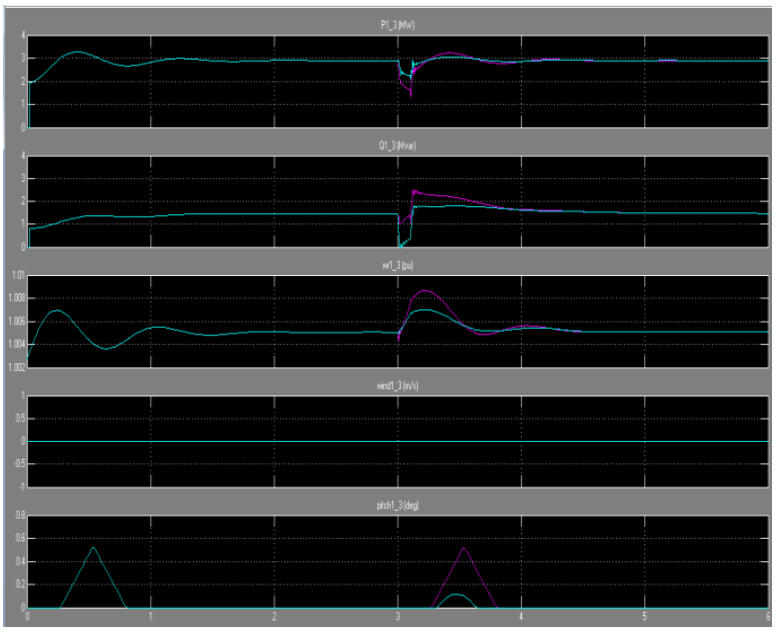

3.3(b) at generators

Fig.3.3. Response of the system under LLG fault (0.1 sec.) at Generator 2 without STATCOM

Fig. 3.3 \& Fig. 3.4 shows that the studied system is subjected to phase to phase to ground fault occurred at wind turbine 2 only and cleared after $(0.1 \mathrm{~s})$ from $3 \mathrm{sec}$ to $3.1 \mathrm{sec}$. It can be observed from Fig. 3.3(b) the output active power for each pair of turbine is $3 \mathrm{MW}$, absorbed reactive power for each pair of turbine reaches to $1.47 \mathrm{Mvar}$, turbine speed for each pair of turbine reaches to $1.005 \mathrm{pu}$. Because of the lack of reactive power support the voltage at bus $25 \mathrm{kV}$ now drops to $0.95 \mathrm{pu}$ as shown in Fig. 3.3(a). While with STATCOM the output active power for each pair of wind turbine reaches to $3 \mathrm{MW}$, absorbed reactive power for each pair of turbine reaches $1.47 \mathrm{Mvar}$, turbine speed for each pair of turbine reaches to $1.0045 \mathrm{pu}$ as shown in Fig. 3.4(b). With respect bus $25 \mathrm{kV}$, voltage reaches to $1 \mathrm{pu}$ in Fig. 3.4(a), active power reaches to $9 \mathrm{MW}$ and absorbed reactive power reaches $2 \mathrm{Mvar}$. 


\section{International Journal of Advanced Research in Electrical, Electronics and Instrumentation Engineering}

(An ISO 3297: 2007 Certified Organization)

\section{Vol. 3, Issue 9, September 2014}

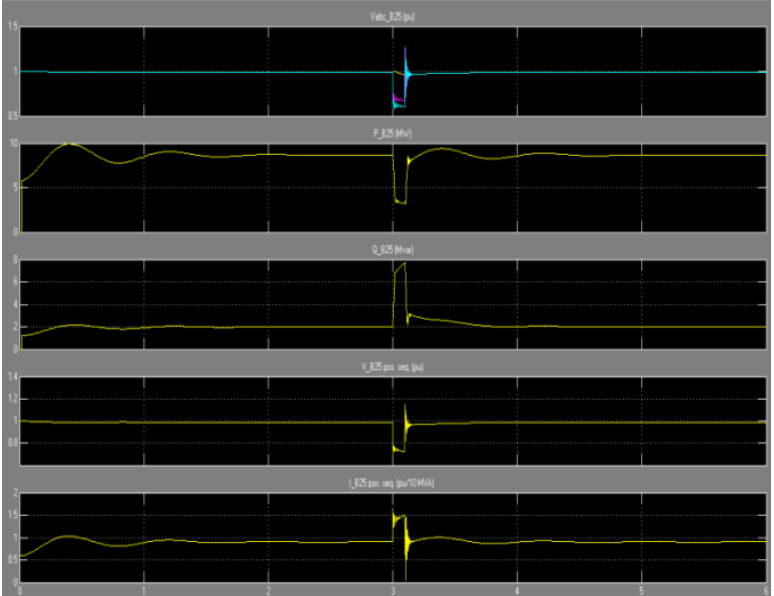

3.4(a) at system bus

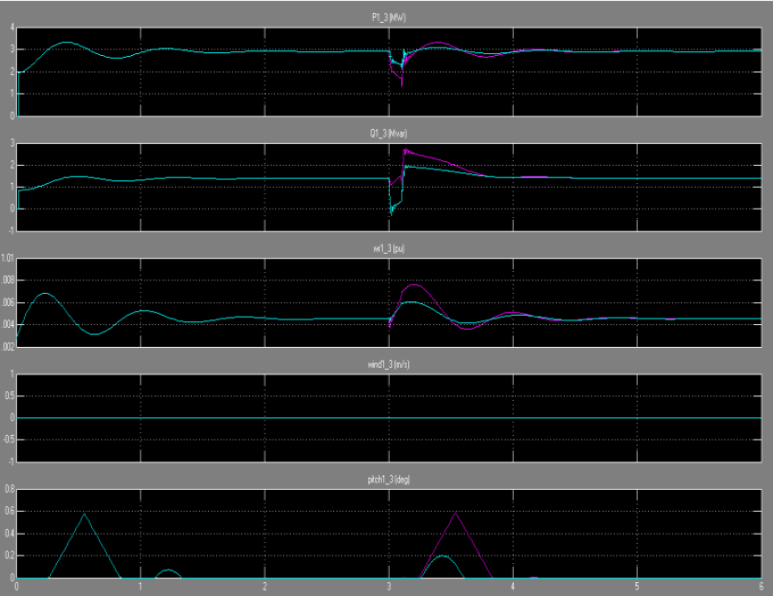

3.4(b) at generators

Fig.3.4. Response of the system under LLG fault (0.1 sec.) at Generator 2 with STATCOM CASE 3: THREE PHASE FAULT CONDITION

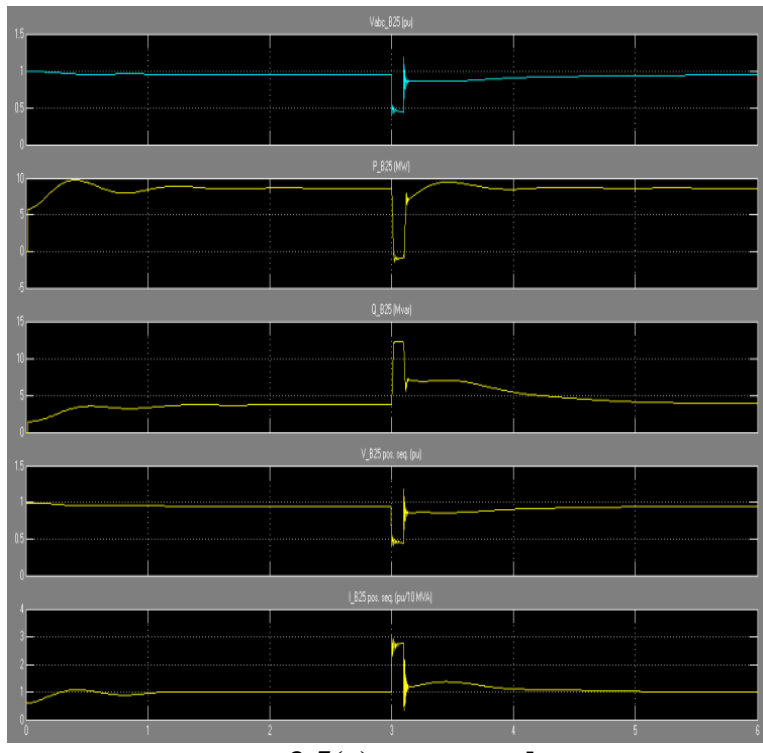

3.5(a) at system bus

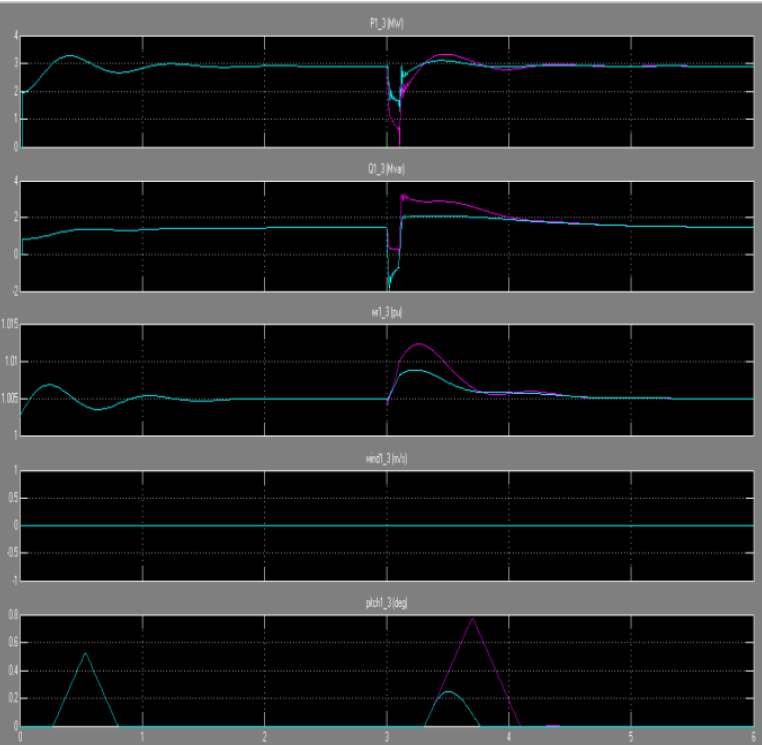

3.5(b) at generators

Fig.3.5. Response of the system under LLL fault (0.1 sec.) at Generator 2 without STATCOM

Fig.3.5 \& Fig.3.6 shows the studied system was subjected to three phase fault occurred at wind turbine 2 only and cleared after $100 \mathrm{~ms}$. Without STATCOM, it is clear that because of the lack of reactive power support the voltage at bus $25 \mathrm{kV}$, drops to $0.92 \mathrm{pu}$. While with STATCOM the voltage at bus $25 \mathrm{kV}$, reaches to $1 \mathrm{pu}$. 


\section{International Journal of Advanced Research in Electrical,} Electronics and Instrumentation Engineering

(An ISO 3297: 2007 Certified Organization)

\section{Vol. 3, Issue 9, September 2014}

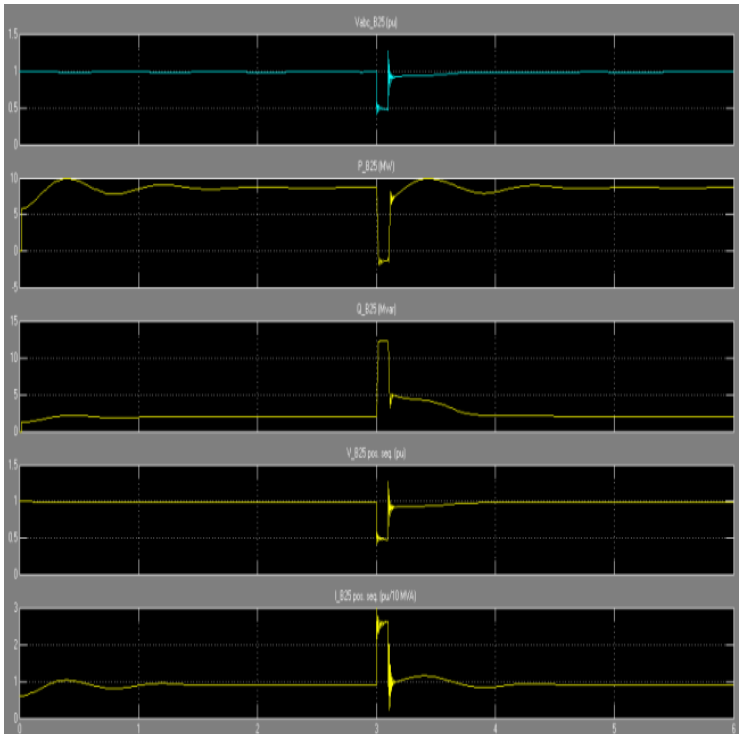

3.6(a) at system bus

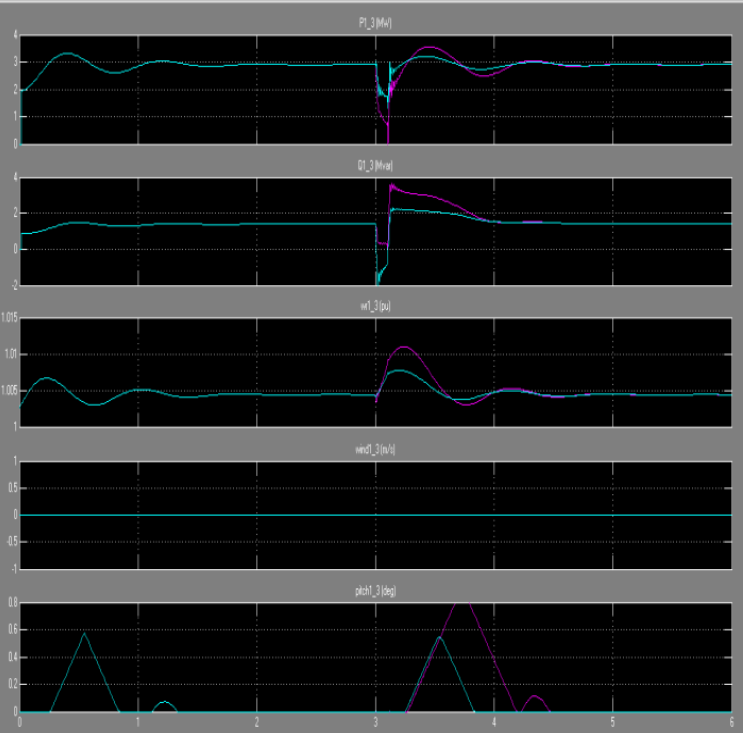

3.6(b) at generators

Fig.3.6. Response of the system under LLL fault (0.1 sec.) at Generator 2 with STATCOM

In Fig. 3.3(b), Fig. 3.4(b), Fig. 3.5(b), Fig. 3.6(b) the waveform in pink colour shows the wind turbine 2 characteristics and the waveform in blue colour shows wind turbine $1 \&$ wind turbine 3 characteristics as the fault is created at generator 2 .

IV.RESPONSE OF THE SYSTEM WITH 3 MVAR STATCOM WHEN FAULT IS AT BUS 25 at (3ms - 3.1 ms) CASE 2: PHASE-PHASE TO GROUND FAULT CONDITION

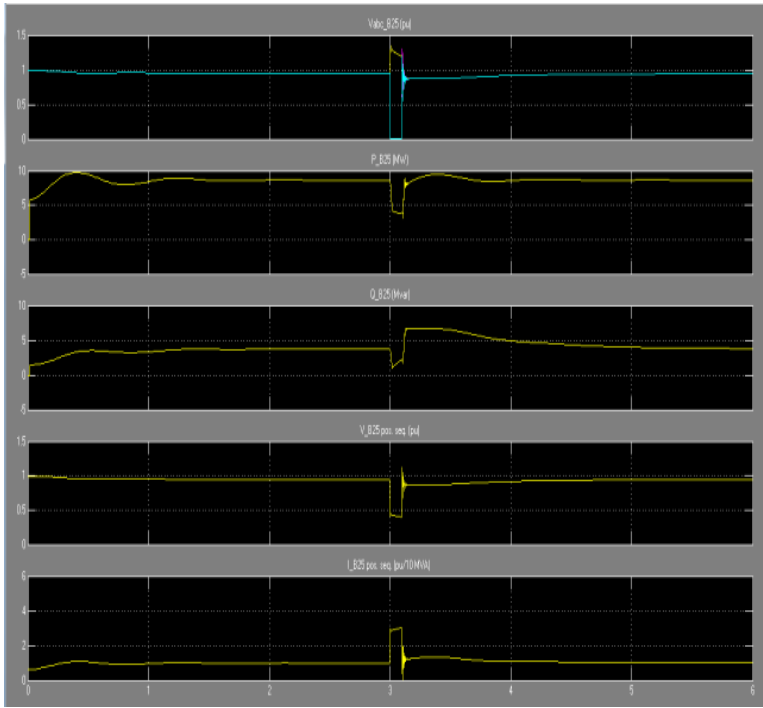

3.7(a) at system bus

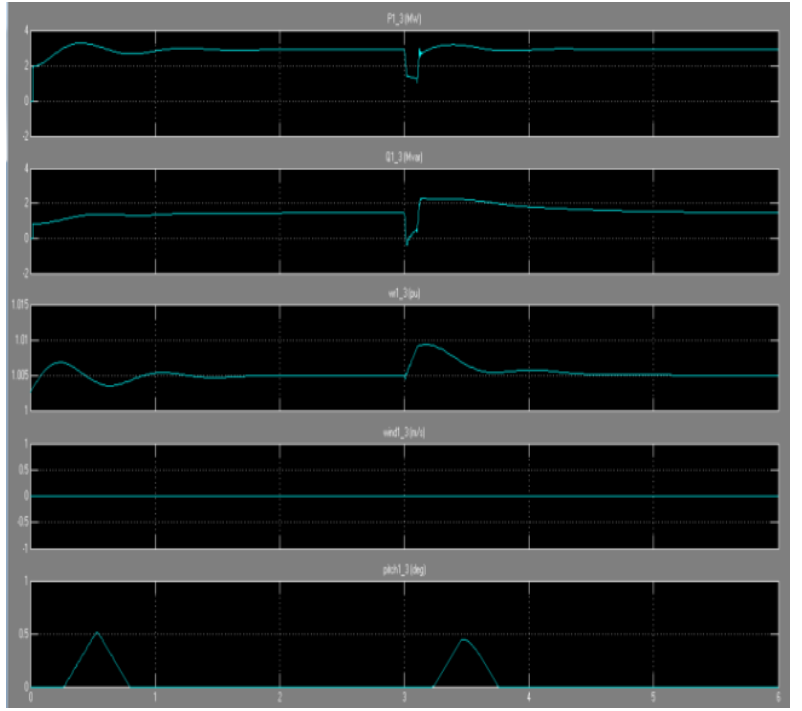

3.7(b) at generators

Fig.3.7. Response of the system under LLG fault (0.1 sec.) at Bus 25 without STATCOM 


\section{International Journal of Advanced Research in Electrical, Electronics and Instrumentation Engineering}

\section{(An ISO 3297: 2007 Certified Organization)}

\section{Vol. 3, Issue 9, September 2014}

Fig. 3.7 \& Fig. 3.8 shows that the studied system is subjected to phase to phase to ground fault occurred at bus 25 and cleared after (0.1s) from $3 \mathrm{sec}$ to $3.1 \mathrm{sec}$. It can be observed from Fig. 3.7(b) the output active power for each pair of turbine is $3 \mathrm{MW}$, absorbed reactive power for each pair of turbine reaches to $1.47 \mathrm{Mvar}$, turbine speed for each pair of turbine reaches to $1.005 \mathrm{pu}$. Because of the lack of reactive power support the voltage at bus $25 \mathrm{kV}$ now drops to $0.95 \mathrm{pu}$ as shown in Fig. 3.7(a). While with STATCOM the output active power for each pair of wind turbine reaches to 3MW, absorbed reactive power for each pair of turbine reaches 1.47Mvar, turbine speed for each pair of turbine reaches to $1.0045 \mathrm{pu}$ as shown in Fig. 3.8(b). With respect bus $25 \mathrm{kV}$, voltage reaches to 1pu in Fig. 3.8(a), active power reaches to $9 \mathrm{MW}$ and absorbed reactive power reaches $2 \mathrm{Mvar}$.

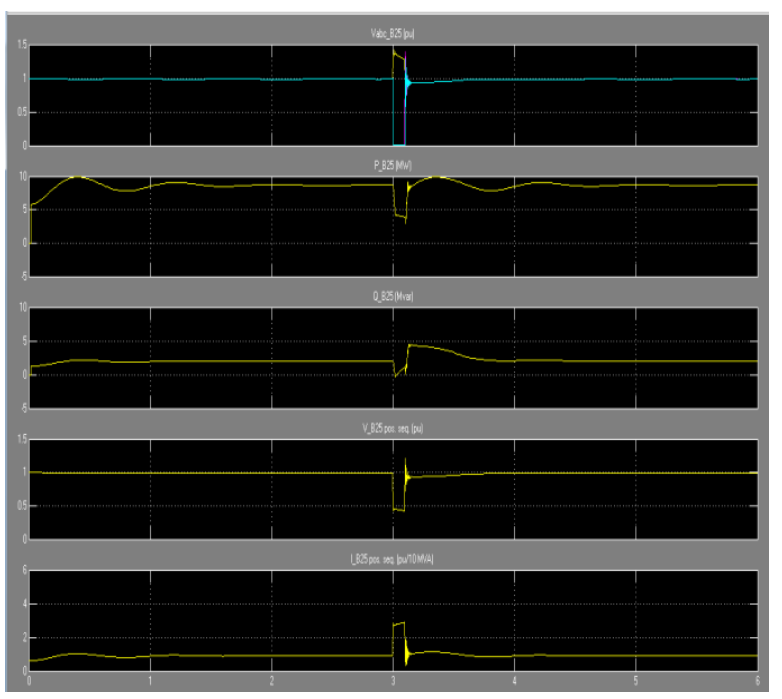

3.8(a) at system bus

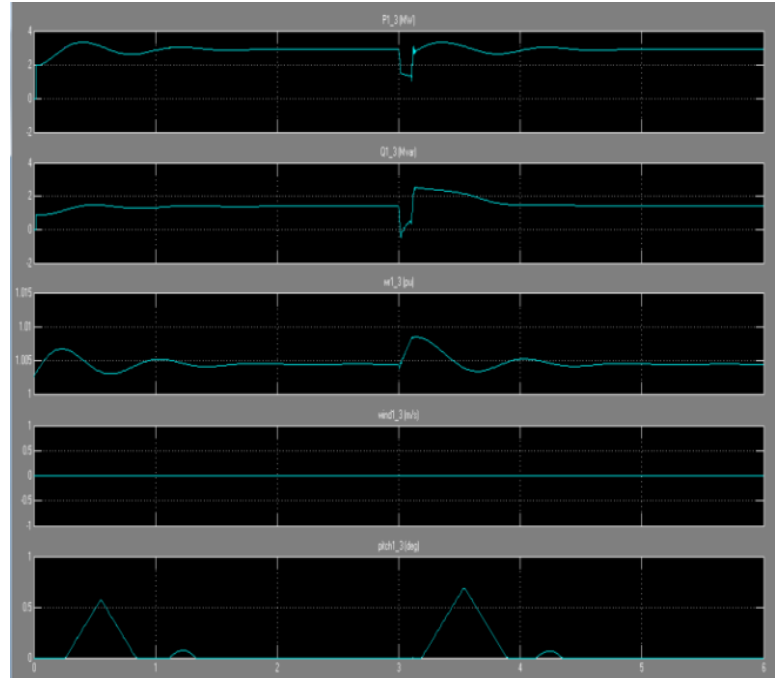

3.8(b) at generators

Fig.3.8. Response of the system under LLG fault (0.1 sec.) at Bus 25 with STATCOM

CASE 3: THREE PHASE FAULT CONDITION

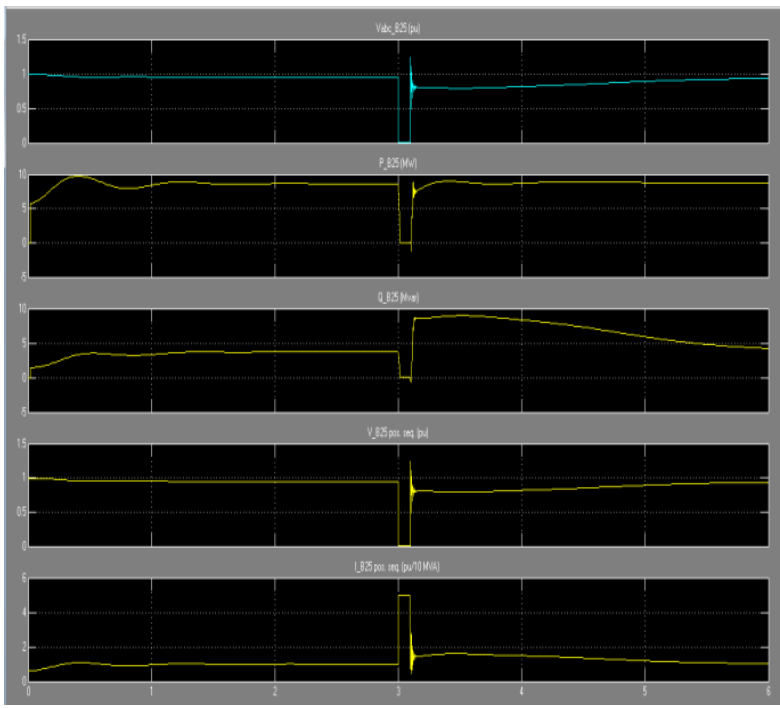

3.9(a) at system bus

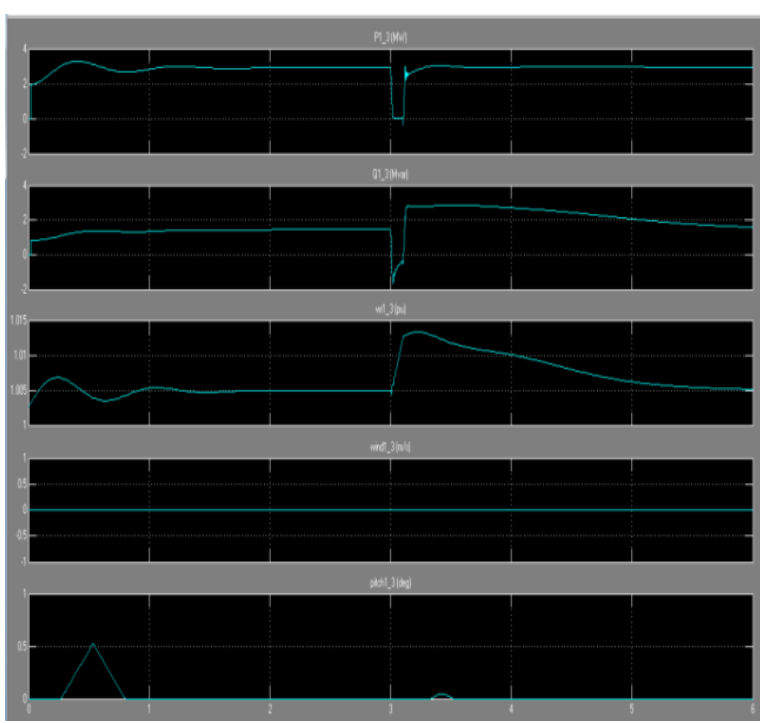

3.9(b) at generators

Fig.3.9. Response of the system under LLL fault (0.1 sec.) at Bus 25 without STATCOM 


\section{International Journal of Advanced Research in Electrical, Electronics and Instrumentation Engineering}

\section{(An ISO 3297: 2007 Certified Organization)}

\section{Vol. 3, Issue 9, September 2014}

Fig.3.9 \& Fig.3.10 shows the studied system was subjected to three phase fault occurred at Bus 25 and cleared after $100 \mathrm{~ms}$. Without STATCOM, it is clear that because of the lack of reactive power support the voltage at bus $25 \mathrm{kV}$ drops to 0.92 pu as shown in Fig. 3.9(a). While with STATCOM the voltage at bus $25 \mathrm{kV}$, reaches to $1 \mathrm{pu}$ in Fig. $3.10(\mathrm{a})$.

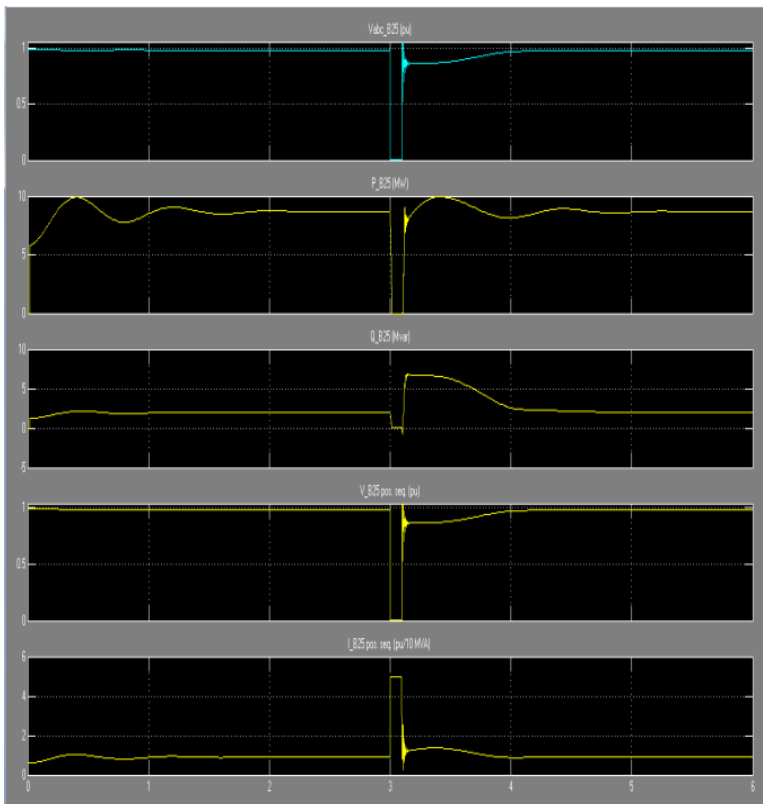

3.10(a) at system bus

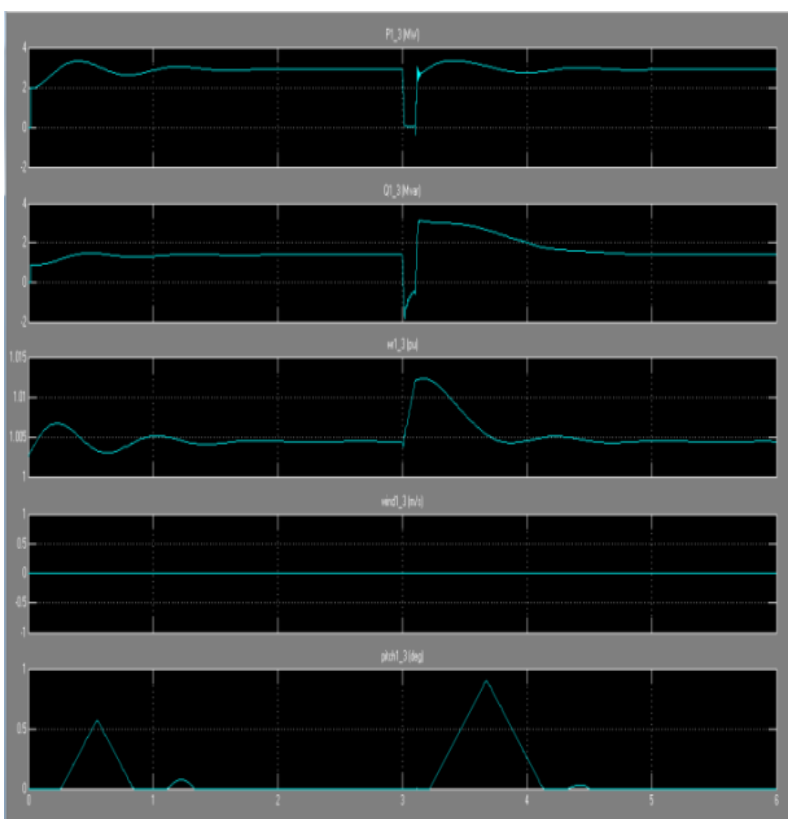

$3.10(b)$ at generators

Fig.3.10. Response of the system under LLL fault (0.1 sec.) at Bus 25 with STATCOM

In Fig. 3.7(b), Fig. 3.8(b), Fig. 3.9(b), Fig. 3.10(b) shows the same characteristics of waveform for wind turbine 1, wind turbine $2 \&$ wind turbine 3 as the fault is created at bus 25 .

\section{V.CONCLUSION}

Power system with wind farms performance can be improved using FACTS devices such as STATCOM. The dynamic model of the studied power system is simulated using Simulink Matlab package software.

To validate the effect of the STATCOM controller of power system operation, the system is subjected to different disturbances such as faults and power operating conditions. The digital results prove the powerful of the proposed STATCOM controller in terms of Stability improvement, power swings damping, voltage regulation, and an increase of power transmission and chiefly as a supplier of controllable reactive power to accelerate voltage recovery after fault occurrence.

\section{REFERENCES}

1. N. G. Hingorani and L. Gyugyi, "Understanding FACTS: Concepts and Technology of Flexible AC Transmission Systems", IEEE, New York, 2000, ISBN 0-7803, pp. 3455-3458, 2000

2. Lie Xu Liangzhong Yao Sasse, C.," Comparison of using SVC and STATCOM for wind farm integration", International Conference on Power System Technology, pp. 1-7, Oct 2006.

3. EL-Moursi, M.S. and Sharaf, A.M, "Novel STATCOM controllers for voltage stabilization of wind energy scheme", Volume: 20 , pp. 1985 1997, Nov 2005.

4. Rajiv K. Varma, Vinod Khadkikar, and Ravi Seethapathy, "Nighttime Application of PV Solar Farm as STATCOM to Regulate Grid Voltage", IEEE TRANSACTIONS ON ENERGY CONVERSION, VOL. 24, NO. 4, DECEMBER 2009.

5. Foster, S.Queen's Univ. Belfast, Belfast Xu, L.; Fox, B.,"Grid Integration of Wind Farms Using SVC and STATCOM",Universities Power Engineering Conference, 2006. UPEC '06. 


\title{
International Journal of Advanced Research in Electrical, Electronics and Instrumentation Engineering
}

\author{
(An ISO 3297: 2007 Certified Organization)
}

Vol. 3, Issue 9, September 2014

6. J.B.Ekanayake, "SELECTION OF PASSIVE ELEMENTS FOR A THREE LEVEL INVERTER BASED STATIC SYNCHRONOUS COMPENSATOR", IEEE Transactions on Power Delivery, Vol. 14, No. 2, April 1999.

7. Wessels, C.," Voltage control of a StatCom at a fixed speed wind farm under unbalanced grid faults", IECON 2011 - 37th Annual Conference on IEEE Industrial Electronics Society, Nov. 2011.

\section{BIOGRAPHY}

K.B.Mohd.Umar Ansari was born in Port Blair, Andaman \& Nicobar Islands, India, received the B.E. Degree in Electrical and Electronics Engineering from St. Peter's Engineering College affiliated to Anna University, Chennai after which he was employed by Meerut International Institute of Technology, Meerut, India. He has worked there as a Lecturer. Currently, he is interested to research topics include Power Electronics, Neural network and Fuzzy logic controllers. He is currently a M.Tech. Candidate in Electrical Power \& Energy Systems at Ajay Kumar Garg Engineering College, Ghaziabad, Affiliated to Uttar Pradesh Technical University, Lucknow, Uttar Pradesh, India. 